\title{
NEOCONSTITUCIONALISMO, NEOPROCESSUALISMO E A TUTELA ADEQUADA DOS DIREITOS TRANSINDIVIDUAIS
}

\author{
ALINE MAIA SANTOS ${ }^{1}$ \\ GUSTAVO VIEGAS MARCONDES ${ }^{2}$ \\ JAQUELINE QUERINO ALVES ${ }^{3}$ \\ FLÁVIA DE ALMEIDA MONTINGELLI ZANFERDINI ${ }^{4}$
}

\begin{abstract}
RESUMO: O presente artigo abordará alguns aspectos da constitucionalização do Direito ocorridas a partir do fenômeno do Neoconstitucionalismo, que trouxe consigo transformações substanciais na forma de se interpretar o Direito, que culminaram no fortalecimento da Jurisdição Constitucional, bem como na prestação adequada da Tutela dos Direitos Transindividuais.

PALAVRAS-CHAVE: Neoconstitucionalismo; Neoprocessualismo; Hermenêutica Constitucional; Direitos Transindividuais.

ABSTRACT: This article will address some aspects of the constitutionalization of the law that occurred since the phenomenon of Neoconstitutionalism, which brought substancial change in the way of interpreting the law that resulted in the strengthening of the Constitutional Jurisdiction, as well as providing adequate protection of the transindividual rights.

KEY-WORDS: Neoconstitutionalism; Constitutional Hermeneutics; Transindividual Rights.

SUMÁRIO: Introdução; 1 Neoconstitucionalismo; 2 Hermenêutica (Neo)Constitucional; 3 Jurisdição Constitucional e a Tutela Adequada dos Direitos Transindividuais; Considerações Finais; Referências.
\end{abstract}

Artigo recebido em 15.08.2011. Pareceres emitidos em 23.09.2011 e 11.10.2011.

Artigo aceito para publicação em 08.01.2012.

${ }^{1}$ Mestranda em Direito Processual Coletivo pela Universidade de Ribeirão Preto-SP. Professora Universitária na Faculdade Pitágoras de Uberlândia - MG. Advogada. aline_maia0907@hotmail.com ${ }^{2}$ Mestrando em Direito Processual Coletivo pela Universidade de Ribeirão Preto-SP. Advogado. gustavo.marcondes@cgmv.com.br

${ }^{3}$ Mestranda em Direito Processual Coletivo pela Universidade de Ribeirão Preto-SP. Mestranda em Química Forense pela Universidade de São Paulo - campus Ribeirão Preto. Advogada. jacqueline.querino@hotmail.com

${ }^{4}$ Mestre e Doutora em Direito Processual Civil pela Pontifícia Universidade Católica/SP. Juíza de Direito. Professora do curso de Mestrado em Direito da Universidade de Ribeirão Preto-SP. fzanferdini@hotmail.com 
CONTENTS: Introduction; 1 Neoconstitutionalism; 2 (Neo)Constitutional Hermeneutics; 3 Constitutional Jurisdiction and the Adequate Custody of the Transindividual Rights; Final Considerations; References.

\section{INTRODUÇÃO}

Neste trabalho analisou-se o Neoconstitucionalismo, e procurou-se demonstrar as transformações de paradigmas de interpretação do Direito, bem como o fortalecimento da Jurisdição Constitucional por meio do manejo dos instrumentos constitucionais existentes, que permitem a adequada tutela dos Direitos Transindividuais.

Ao conferir status de norma suprema à Constituição Federal, o EstadoJuiz viu-se obrigado a cumprir o rol de Direitos Fundamentais nela inseridos. Assim, independente da existência de lei infraconstitucional, toda a carga axiológica e principiológica garantidora de direitos existentes no texto deixaram o plano meramente teórico ou "programático" e passaram a demandar efetividade.

Necessário frisar que o Neoconstitucionalismo conferiu especial importância e força ao Poder Judiciário - destaque que antes pertencia ao Legislativo e que passou agora para o poderio do Estado-Juiz.

Resta analisar o papel do Poder Judiciário nesse contexto do Neoconstitucionalismo.

Essa perspectiva de análise decorre da própria natureza de tal categoria de direitos, na medida em que é a titularidade indeterminada que melhor os define e caracteriza, ou seja, trata-se de direitos que são, ao mesmo tempo, de todos e de ninguém especificamente. São direitos e interesses comuns a toda a sociedade.

Por outro lado, conquanto reconhecida a existência de direitos dessa natureza, é justamente a inexistência de um titular certo e determinado que traz consigo a necessidade de desenvolvimento de parâmetros claros e uniformes de exercício e tutela jurisdicional de tais direitos, na medida em que não se pode relegar ao próprio "titular" a iniciativa de resguardo do direito, tal como se dá no âmbito dos interesses privados individuais. Além disso, conforme se verá adiante, a transindividualidade do interesse importa também em um alto grau de conflituosidade interna, ou seja, na existência constante de um interesse transindividual em conflito com outro ou outros interesses igualmente transindividuais.

Significa afirmar que uma nova categoria de direitos se faz presente e exige nova abordagem processual, que seja mais condizente com a relevância metaindividual do bem da vida juridicamente protegido, preservando, porém, tanto quanto possível, a organicidade e cientificidade do sistema processual.

Surge, nesse contexto, a necessidade de conjugação desse tratamento processual próprio e específico voltado aos conflitos que envolvam direitos transindividuais e o papel a ser desempenhado pelo Poder Judiciário numa 
realidade jurídica em que a mera dicção do Direito aplicável ao caso concreto já não basta à pacificação social, ou seja, não basta ao próprio Direito.

Esse papel diferenciado que passa a ser exigido do Poder Judiciário encontra forte respaldo teórico no pensamento jurídico constitucional ocidental que marcou, sobretudo, a segunda metade do século $X X$, denominado neoconstitucionalismo. Sua vertente processual (o neoprocessualismo) também se apresenta como arcabouço teórico para a construção e desenvolvimento de uma abordagem jurisdicional adequada a esses conflitos transindividuais, tendo em conta, substancialmente, que a transindividualidade que marca a pretensão também se encontra, em igual medida, muitas vezes, na resistência à pretensão. Daí a necessidade de uma tutela adequada para tais direitos, que atenda à finalidade constitucional que os guarnece.

\section{NEOCONSTITUCIONALISMO E NEOPROCESSUALISMO}

Tendo como marco temporal a segunda metade do século $\mathrm{XX}, 0$ neoconstitucionalismo significou a passagem do Estado Legislativo para 0 Estado Constitucional, o que, para Ferrajoli (FERRAJOLI: 2002), demonstra a passagem do Estado débil para o Estado forte.

A Lei Fundamental de Bonn, em 1949, na Alemanha, apresenta-se historicamente como marco ao referir-se às realidades Lei e Direito como distintas. A partir de então, restou superada a sinonímia entre Lei e Direito, que havia sido consagrada com a Revolução Francesa.

Nesse contexto, não se concebe mais a redução do juiz a ser a "boca inanimada da lei", cabendo-Ihe dizer não apenas o direito legal, mas também o direito constitucional.

Anteriormente a esse novel pensamento, as Constituições eram tratadas como meros documentos políticos, pois não gozavam da característica de "norma fundamental", com prevalência sobre qualquer outra.

Segundo Luís Roberto Barroso (BARROSO: 2007, p.20) três grandes transformações subverteram o conhecimento convencional relativamente à aplicação do direito constitucional: a) o reconhecimento de força normativa à Constituição; b) a expansão da jurisdição constitucional; c) o desenvolvimento de uma nova dogmática de interpretação constitucional.

Justamente por essa razão é que as normas constitucionais deverão ser efetivas. Dentro de tal perspectiva, cada vez mais se reconhece a importância da difusão da utilização das Ações Constitucionais.

Desse modo, é inadmissível que não se efetive uma prerrogativa ou garantia constitucional com o simples argumento de omissão legislativa ou ainda de lacunas na lei, posto que, o neoconstitucionalismo, segundo o marco teórico que o delimita, elevou a Constituição ao status de norma jurídica superior, conferindo maior amplitude de atuação do Poder Judiciário o que invariavelmente determinou novas formas de interpretação constitucional, conforme se demonstrará no próximo tópico. 
Nesse sentido, fica consagrado que o dever do magistrado não se subsume mais em apenas dizer o Direito (iuris dictio) apenas em seu conjunto de normas infra constitucionais, mas sobretudo, dizer o Direito a partir da matiz constitucional.

É possível afirmar que no final do Século $X X$, as Cartas Constitucionais adquiriram, de forma generalizada, uma função unificadora, já que consagraram uma solução final perante conflitos e antinomias, empregando sua eficácia inclusive contra legisladores o que faz com que a noção de Constituição seja mais profunda e apaziguadora de conflitos que o princípio da legalidade, propondo que haja, assim, uma tendência à unificação pelo constitucionalismo (ZAGREBELKY: 2009, p. 263).

Compreender a relação existente entre a maneira pela qual a jurisdição deve ser adequadamente prestada nos conflitos transindividuais e o respaldo constitucional conferido a essa peculiar forma de tutela jurisdicional significa (re)compreender não apenas o papel desempenhado pela Constituição num dado sistema jurídico, como também o papel desempenhado pelo Poder Judiciário e seus respectivos atores.

É certo que não se pode afirmar ser a Constituição um documento dotado de uma única faceta. Com efeito, para além da expressão cultural de um determinado povo, num determinado momento histórico e num dado território, a Constituição é também o arcabouço fundamental de divisão e distribuição de poderes e competências; do estabelecimento de regras específicas de organização e funcionamento do Estado; do estabelecimento de direitos e garantias fundamentais individuais e coletivos e, sobretudo, da consagração de princípios e valores essenciais para aquele determinado povo, naquele determinado território, naquele determinado momento histórico.

A eleição de valores e princípios essenciais e a sua consagração no bojo do texto jurídico mais importante de uma dada nação marcou, de certa maneira, essa mudança paradigmática que se denomina neoconstitucionalimo, fenômeno assim compreendido por André Rufino do Vale:

[...] pode-se traçar o seguinte perfil do constitucionalismo contemporâneo: mais princípios que regras; mais ponderação que subsunção; mais Constituição que lei; mais juiz que legislador

Não se trata, portanto, de um movimento, mas de um conjunto de posturas teóricas que adquiriram sentidos comuns ao tentar explicar o direito dos Estados constitucionais, especificamente aqueles que, a partir do segundo pós-guerra, em momentos históricos de repúdio aos recémdepostos regimes autoritários, adotaram constituições caracterizadas pela forte presença de direitos, princípios e valores e de mecanismos rígidos de fiscalização da constitucionalidade - manejados por um órgão jurisdicional especializado, normalmente o Tribunal Constitucional como as constituições da Itália (1948), Alemanha (1949) e Espanha (1978), contexto no qual as Constituições de Portugal (1976) e do Brasil (1988) inserem-se perfeitamente. (VALE: 2007, p. 68) 
Trata-se, com efeito, da contitucionalização do direito vigente (VIGO: 2009 , p. 345), profunda alteração paradigmática que trouxe para o seio da Constituição institutos jurídicos afetos a direitos e interesses que, embora relevantes, antes não assumiam esse papel, tampouco contavam com 0 status normativo inerente à norma hierarquicamente superior.

O Direito Constitucional, sem dúvida, tem se mostrado o ramo do Direito mais sensível a todas as mudanças que atingem a sociedade como um todo, em suas matizes políticas e econômicas vivenciadas não apenas no âmbito interno, mas também no âmbito internacional, sobretudo, a partir do segundo pós-guerra. Essas mudanças não por acaso, também foram responsáveis pelo próprio surgimento e desenvolvimento dos novos direitos a que se fez menção alhures.

Segundo Fernanda Dias Menezes de Almeida, no caso brasileiro, a estrutura tópica adotada pela Constituição Federal de 1988 acabou por contemplar, com maior ou menor prevalência de uma sobre outras, todas as três gerações de direitos humanos identificadas até então, destacando-se que, no tocante aos denominados novos direitos houve verdadeira inovação normativa, uma vez que, especialmente naquele momento, não havia plena compreensão a respeito do conteúdo de tais direitos e, ainda assim, foram trazidos para o seio da Constituição.

A autora destaca que:

Por fim, e aqui inovando no Direito Constitucional brasileiro, a Constituição também dedica atenção aos chamados direitos de terceira geração, de matriz internacional, identificados a partir da década de 1970 como direitos de solidariedade entre os povos e cujo reconhecimento como verdadeiros direitos ainda suscita controvérsias, preferindo alguns considerá-los meras aspirações. Menos divulgados do que os de sedimentação mais antiga, vale a pena ao menos esclarecer que como direitos de terceira geração têm sido apontados o direito à paz, o direito ao desenvolvimento, o direito a um patrimônio comum da humanidade, o direito ao meio ambiente ecologicamente equilibrado. (ALMEIDA: 2008, p. 45)

Antônio Junqueira de Azevedo, por sua vez, também aponta essa permeabilidade do Direito Constitucional às mudanças no plano social, econômico e tecnológico e enfatiza que, após o declínio do modelo liberal que marcou o século XIX e início do século XX, houve a necessidade de se encontrar novos modelos jurídicos que não apenas se ativessem à objetividade do silogismo aristotélico da Lei geral e abstrata, destacando que:

Sob o paradigma da lei, a maneira de conceber o Direito correspondia perfeitamente à mentalidade democrática e individualista das nações ocidentais, no século XIX e começo do século XX. Entretanto, os movimentos sociais, as revoluções, as guerras, os campos de extermínio, 
em todo o decorrer do século $X X$, puseram em xeque aquela confiança na lei como expressão da vontade coletiva. Especialmente, após a $2^{\mathrm{a}}$ Grande Guerra, os juristas, consciente ou inconscientemente, voltaram a procurar algo que pudesse evitar tanta tragédia para o ser humano. O simples Direito positivo, afinal, não foi suficiente para impedir a barbárie. Alguns juristas voltaram a falar em "Direito Supralegal" (evitando a expressão "Direito Natural" (Bachof, o. c., passim), mas a maior parte procurou reforçar a Constituição e os direitos humanos, até mesmo formulando novas declarações de direitos, válidas quaisquer que fossem o Estado e seu regime político. (AZEVEDO: 2008, p. 4)

É possível, então, vislumbrar que essa característica maleável do Direito Constitucional se deve a uma conjunção de fatores, dentre os quais poderíamos destacar o fato de se tratar da norma jurídica hierarquicamente superior, responsável pela organização do Estado, definição e distribuição de competências, definição de limites de atuação e limites de ingerência do Estado na vida dos particulares e, principalmente, responsável pela higidez das garantias e liberdades e pela orientação de todo o ordenamento jurídico, bem como sua efetiva aplicação ao caso concreto.

E, justamente por se tratar da norma jurídica superior, voltada ao próprio Estado, essa organização se dá em torno de uma proposta estatal ideologicamente orientada e axiologicamente comprometida, cuja concretização passa a ser difusamente observada, na solução dada aos casos concretos levados ao Poder Judiciário.

A inserção de tais valores no documento jurídico mais relevante, hierarquicamente superior e, mais do que isso, dotando-se tais valores e princípios de conteúdo normativo próprio, para além de uma mera declaração ou exortação de direitos, culminou com o reconhecimento do poder de coercitibilidade e exigibilidade imediata da concretização daqueles valores e princípios. A Constituição como norma jurídica eficaz passa a ter operatividade direta, ou seja, deixa de ser repositório de meras normas pragmáticas.

Para Eduardo Cambi (2006, p. 663), essa mudança paradigmática na compreensão do Direito Constitucional caracteriza-se por fatores de ordem histórica, filosófica e teórica. Aponta o autor que essa concepção constitucional ganhou força após a derrocada dos regimes totalitários, especialmente os de cores nazi-fascistas, quando houve uma maior necessidade de se conferir proteção jurídica diferenciada ao cidadão contra o Estado. No entanto, diferentemente do que ocorreu no período das revoluções burguesas, o valor dignidade da pessoa humana passou a ser considerado preponderante e axiologicamente superior a outros valores, inclusive a própria liberdade.

Com a incorporação ao texto constitucional de valores e princípios, por meio de normas dotadas de conteúdo normativo efetivo, a Constituição deixa, então, de ser mera fonte de preceitos programáticos, de pouca ou duvidosa efetividade, para ser fonte de preceitos normativos diretos. 
Daí a expansão da jurisdição constitucional apontada por Luís Roberto Barroso, na medida em que o controle da constitucionalidade das normas e atos do Poder Público passa a fazer parte do cotidiano nas mais comezinhas disputas judiciais. No caso brasileiro, em virtude do controle difuso de constitucionalidade, que pode ser praticado no caso concreto, como fundamento de decidir e efeitos incidenter tantum, essa característica se mostra ainda mais marcante.

Trouxe-se, assim, a Constituição para o plano das disputas "terrenas", fazendo com que a concretização dos valores constitucionais também passasse a fazer parte da resolução efetiva desses conflitos, e não apenas a Lei infraconstitucional. Houve, portanto, o desenvolvimento de um modelo argumentativo extremamente sofisticado de aplicação do Direito, em detrimento de um modelo meramente silogístico de resolução de conflitos por meio de soluções preconcebidas e dadas "aritmeticamente" pela Lei.

Isso se deve em razão da própria diferença de natureza da norma constitucional e da norma infraconstitucional. Enquanto esta contém, em geral, regras objetivas para a resolução de uma dada hipótese de conflito, as normas constitucionais contêm, em geral, princípios e valores aplicáveis a qualquer modalidade de conflito. Tais princípios e valores, por sua vez, demandam do aplicador do Direito maior sutileza ao proferir a decisão, visto que the cabe o preenchimento de sentido e significado - inclusive semântico - dos preceitos consagrados pelo texto constitucional.

Veja-se, todavia, que não se trata, singelamente, de preencher conteúdos jurídicos dados por normas que se enquadrem nas clássicas definições de cláusulas gerais ou conceitos jurídicos indeterminados. Não se trata, portanto, simplesmente de uma mudança de paradigmas conceituais e culturais a respeito do que se deve compreender por determinada expressão ou conceito jurídico.

No caso da jurisdição constitucional inerente ao neoconstitucionalismo, o que se tem é a própria compreensão do conteúdo axiológico do princípio em questão, aliado ao modo pelo qual determinado princípio é empregado na solução do caso concreto. Compreensão essa que, à toda evidência, se faz em bases fundamentalmente subjetivas do julgador, no momento em que se explicitam os argumentos que conduzem a uma determinada solução jurídica para o conflito posto.

Esse incremento de fundamentação jurídica, de envergadura constitucional, voltada para a resolução dos conflitos, sejam eles individuais ou coletivos, públicos ou privados, por sua vez, impulsionou o desenvolvimento da nova dogmática constitucional em que a resolução do litígio leva em consideração a ponderação de princípios.

2 HERMENÊUTICA (NEO)CONSTITUCIONAL

Com o advento do neoconstitucionalismo, os métodos de interpretação clássicos e tradicionais tiveram que ser relegados a segundo plano, cedendo 
espaço às novas formas de se conceber e criar o Direito a partir de uma leitura constitucionalizada alicerçada em métodos inovadores.

Ainda que persista a utilização de métodos tais como o gramatical, histórico, sistemático e o teleológico, o neoconstitucionalismo fez emergir para o Direito Constitucional princípios específicos de interpretação, já que sem tais ferramentas não seria possível revelar os seus valores e critérios para a compreensão e aplicação das normas constitucionais.

Dentre os referidos princípios vetores da hermenêutica constitucional, importa salientar a utilização dos seguintes: supremacia da Constituição, presunção da constitucionalidade das normas e atos do poder público, interpretação conforme a constituição, unidade, proporcionalidade e efetividade.

Importante ressaltar em linhas gerais o que especificamente significa ou determina cada um desses métodos-princípios de interpretação constitucional. O princípio da Supremacia da Constituição estatui como sendo a Constituição o conjunto de normas fundamentais daquele sistema jurídico.

No tocante à presunção de constitucionalidade das normas e atos do poder público diz respeito a presunção relativa (iuris tantum) acerca da legitimidade dos atos do poder público como compatíveis com a Constituição.

A interpretação conforme a Constituição decorre do método de supremacia, submetendo o intérprete a atribuir o significado à norma que mais se compatibilize com o texto constitucional.

O denominado princípio da unidade determina a integração de sentido de todas as normas constitucionais. No que tange ao método da máxima efetividade, prioriza os efeitos que a Constituição irá produzir em face das diversas realidades sociais e, por fim, o princípio da proporcionalidade que busca interpretações mais justas e adequadas, principalmente aptas a solucionar conflitos entre princípios auxiliando o intérprete a ponderar entre bens e interesses em choque.

Tal concepção hermenêutica, criada e voltada exclusivamente para o Direito Constitucional, traz em si a visão do neoconstitucionalismo, qual seja, de que a Constituição apesar de ser um arcabouço de normas está adstrita aos fatos e valores sociais, ganhando assim o intérprete papel relevante, especialmente a figura do juiz.

Nos dizeres de Daniel Sarmento cresceu muito a importância política do Poder Judiciário. Com frequência cada vez maior, questões polêmicas e relevantes para a sociedade passaram a ser decididas por magistrados, e sobretudo por cortes constitucionais, muitas vezes em razão de ações propostas pelo grupo político ou social que fora perdedor na arena legislativa (SARMENTO: 2010). Esse fenômeno tem recebido o nome de Ativismo Judicial (BARROSO: 2007, p. 169).

Segundo o que dispõe Marinoni as normas constitucionais são vinculantes da interpretação das leis, ou seja, explicita o autor que o 
neoconstitucionalismo exige a compreensão crítica da lei em face da Constituição, para ao final fazer surgir uma projeção ou cristalização da norma adequada. (MARINONI: 2009, p. 46)

A vertente processual desse novo modelo de Direito Constitucional, o neoprocessualismo, também apresenta um novo paradigma conceitual da prestação da atividade jurisdicional, agora calcada fortemente na força normativa da Constituição, na hermenêutica constitucional e no novo papel a ser desempenhado pelo juiz na resolução do conflito. Esse novo papel, na realidade, decorre da própria mudança teórica proposta pelo neoconstitucionalismo, visto que um dado conflito poderá encerrar o confronto de dois ou mais princípios jurídicos, ambos de envergadura constitucional, cabendo ao juiz o desenvolvimento de uma hermenêutica que fundamente a preponderância de um sobre outro, naquele dado caso concreto.

Ao pressupor uma prestação jurisdicional que efetivamente concretize princípios consagrados pela Constituição, o neoprocessualismo confere ao juiz a prerrogativa de, diante da ausência da norma infraconstitucional e/ou diante da omissão do Poder Executivo, "avocar" para si os meios de resolução do conflito.

Ora, se na perspectiva do neoconstitucionalismo a solução do conflito passa da mera dedução de uma única solução juridicamente válida e possível para a explicitação do conteúdo normativo das normas constitucionais, cujo conteúdo axiológico apresenta-se aberto, vê-se que a possibilidade de conflito de princípios é, também, inerente a esse paradigma, cabendo ao juiz ponderar esses princípios, dado que eles contam com dimensões de peso ou importância. É dizer, ao intérprete cabe optar por um dos princípios quando entre eles há tensão, procurando adequada solução ao caso concreto.

\section{JURISDIÇÃO CONSTITUCIONAL E A TUTELA ADEQUADA DOS DIREITOS TRANSINDIVIDUAIS}

Luis Roberto Barroso, ao tratar da constitucionalização e judicialização das relações sociais, menciona que ocorreu a irradiação dos valores constitucionais pelo sistema jurídico e tal fato se operacionaliza pela via da jurisdição constitucional, que abrange a aplicação direta da Constituição a determinadas questões; a declaração de inconstitucionalidade de normas com ela incompatíveis; e a interpretação com base na constituição, para atribuição de sentido as normas jurídicas em geral. (BARROSO: 2007, p. 166)

Nesse contexto, Eduardo Cambi menciona que o princípio da adequação do procedimento à causa assume grande relevância, na medida em que o legislador, atento às necessidades do direito material, permite uma tutela jurisdicional mais célere e efetiva. O procedimento do mandado de segurança, exigindo provas pré-constituídas, é um bom exemplo de como um procedimento diferenciado pode contribuir com a tutela célere dos direitos. (CAMBI, 2010, p. 28) 
Especificamente no Brasil a jurisdição constitucional foi ampliada com a instituição dos mecanismos de controle de constitucionalidade, principalmente no tocante ao controle abstrato de constitucionalidade e inconstitucionalidade por omissão, por meio da Ação Direta e do Mandado de Injunção.

Tal perspectiva de análise relaciona tais direitos quase que instintivamente aos instrumentos processuais para sua tutela, na tentativa de sistematizar e uniformizar os mecanismos de definição do meio pelo qual se pede e se entrega a prestação jurisdicional a eles relacionados.

Verifica-se, portanto, que nessa análise teórica a que nos referimos, identificamos na questão da efetividade o ponto nodal do arcabouço teórico a ser desenvolvido, uma vez que encontra no processo, quase que exclusivamente, o campo próprio e adequado para a concretização dessa nova categoria de direitos.

Esse foco de análise teórica se justifica, pois se trata de uma categoria de direitos altamente fluida, de conteúdo indefinido e, não obstante, cada vez mais presente.

É interessante observar, no entanto, que essa vertente de análise teórica, não obstante se mostre em grande medida identificada com as questões afetas diretamente aos mecanismos processuais de conhecimento e resolução das lides massificadas, reclama uma melhor compreensão a respeito do papel desempenhado pelo processo e, consequentemente, pelo próprio Poder Judiciário, na concretização dos direitos transindividuais.

Isso porque, em se tratando de direitos que transcendem o raio de ação e disponibilidade das partes envolvidas no litígio, que não mais representam exclusivamente seus próprios interesses, as decisões oriundas das demandas de massa têm seus efeitos altamente potencializados. Se tais decisões a todos atingem, independentemente da participação no processo, o grau de efetividade conferido pelo processo aos referidos novos direitos, no mais das vezes, ultrapassa aquele decorrente da atuação dos órgãos do Poder Executivo, originariamente incumbido de implementar as iniciativas voltadas à concretização desses direitos.

Vemos, assim, que, nesse contexto, o fim do processo não mais se restringe a mera observância de uma liturgia de formas e atos procedimentais predeterminados, cujo escopo toca apenas ao atingimento de uma decisão jurisdicional que diga o direito aplicável ao caso concreto.

Os conflitos levados ao Poder Judiciário passam a envolver, numa única relação jurídico-processual, inúmeros sujeitos e inúmeros interesses jurídicos, concentrando nas mãos do juiz a incumbência de não apenas pacificar o conflito social (e não exclusivamente das partes diretamente envolvidas no processo), como também de fazer aplicável e concreto um direito cujo objeto é indivisível e cuja titularidade é indeterminada.

Dessa forma, a atuação do Poder Judiciário passa a ganhar cada vez mais contornos de integração principiológica e materialização (concretização) 
de objetivos de Estado, uma vez que a Lei, como comando geral e abstrato proveniente do Poder Legislativo, não mais se mostra suficiente para regulação do convívio social e resolução dos novos tipos de conflitos, não mais protagonizados por sujeitos individualizados, mas sim por coletividades de pessoas e aglutinação de interesses jurídicos.

Nesse sentido, embora atualmente reconheçamos, sem dificuldade, a sua existência, inclusive no plano constitucional e infraconstitucional, esses novos direitos, transindividuais por essência, apresentam peculiaridades que dificultam a definição de padrões uniformes de tutela jurisdicional, embora exijam uma atuação muito mais participativa por parte do Poder Judiciário.

Por outro lado, ao mesmo tempo em que reconhecemos o próprio surgimento dessa nova categoria de direitos, inclusive de novos sujeitos de direitos, agora considerados unitariamente, numa perspectiva coletiva e indivisível, a sua concepção a partir do âmbito constitucional contemporâneo vem merecendo menor entusiasmo doutrinário, a despeito da nítida coloração garantista que tais direitos apresentam e a despeito da mudança do paradigma de prestação da tutela jurisdicional acima apontada.

Isso porque a identificação da origem histórica de qualquer instituto jurídico não se mostra tarefa das mais singelas, sobretudo em se tratando de direitos cujo reconhecimento legislativo ou institucional caminha reativamente ou a reboque de transformações sociais mais ou menos profundas; mais ou menos traumáticas.

No caso do neoconstitucionalismo e dos direitos transindividuais, no entanto, é possível observar ao menos que se trata de fenômenos jurídicos relativamente recentes, relativamente contemporâneos e que ecoam das mesmas mudanças econômicas, políticas, culturais e tecnológicas que marcaram, notadamente, a segunda metade do século $X X$.

É certo que ao se identificar os direitos transindividuais aos assim chamados novos direitos, muitas vezes relacionados aos direitos de terceira geração oriundos dos ideais consagrados pela Revolução Francesa de 1789 (Liberdade, Igualdade e Fraternidade), haverá quem atribua a esta categoria de direitos a precedência cronológica em relação à mudança paradigmática que marca o neoconstitucionalismo. Todavia, essa identificação entre os novos direitos e os direitos de terceira dimensão, em nosso sentir, se deve muito mais ao aspecto ideológico do que ao cronológico.

Na realidade, os direitos de terceira geração não são, necessariamente, uma reedição ou upgrade dos direitos de segunda geração, que também não o são em relação aos direitos de primeira geração. Daí porque preferimos o termo dimensão em lugar de geração (LENZA: 2009).

Nesse sentido, José Emílio Medauar Ommati, frisa que:

No entanto, hoje se pode ver que ao se falar em geração de direitos não se poderia tão somente considerar uma sucessiva cumulação de 
direitos ou até mesmo um progressivo alargamento da efetividade do exercício dos direitos de uma geração passada pelos da geração seguinte: seria necessário reconhecer que tal "cumulação" implica inclusive uma redefenição paradigmática dos "velhos" em "novos" direitos. (2005, p. 475)

Com efeito, apesar de existir uma natural evolução histórica no surgimento e reconhecimento dessas categorias de direitos, cada dimensão representa um matiz próprio e específico, de modo atemporal e não autoexcludentes.

Os direitos de primeira dimensão, associando-se ao valor "liberdade", são direitos e garantias individuais, direcionados (oponíveis) ao Estado, sobretudo, na forma de proibições ou vedações à interferência na vida privada do súdito. São considerados direitos civis ou políticos, especialmente porque balizam a atuação estatal em relação à vida privada do cidadão. Seu surgimento está relacionado às revoluções burguesas do Século XVIII.

Os direitos de segunda dimensão, associados ao valor "igualdade", são direitos que abordam o homem não mais como indivíduo titular de direito, unicamente, mas como indivíduo membro de um grupo, classe ou categoria profissional e, nessa condição, titular de nova categoria de direitos. São direitos associados ao exercício do trabalho, ao sindicalismo e ao associativismo.

Os direitos de terceira dimensão, associados ao valor "fraternidade", são direitos que não se referem ao homem, seja enquanto indivíduo, seja enquanto membro de um determinado grupo. Abordam a humanidade, enquanto valor universal, dissociada de qualquer indivíduo ou grupo de indivíduos, e nessa condição, titular de direitos.

José Eduardo Faria (1997, online) destaca essas características e aponta, também, como cada dimensão de direitos acaba por exigir do Estado uma atuação específica que, no caso dos direitos transindividuais, está umbilicalmente ligada ao papel desempenhado pelo Poder Judiciário como garantidor de eficácia e efetividade desses direitos:

Institucionalizada a partir das lutas anti-absolutistas no século XVIII e da expansão dos movimentos codificados no século XIX, a democracia representativa, como é sabido, foi construída e consolidada ao longo de um processo histórico marcado pelo reconhecimento de três gerações de direitos humanos: os relativos à cidadania civil e política, pensamento, voto, iniciativa, propriedade e disposição de vontade; os relativos à cidadania social e econômica, que se destacam pelo direito à educação, à saúde, à segurança social e econômica e ao bem estar, tanto individual quanto coletivo concedidos às classes trabalhadoras; os relativos à cidadania pós-material, que se destacam pelo direito à qualidade de vida, ao meio ambiente saudável, à tutela dos interesses difusos, ao reconhecimento da diferença, da singularidade e da subjetividade 
(Bendix, 1977; Ferry \& Renault, 1985; Capella, 1993; Santos, 1995). Essas três gerações de direitos humanos gravitam, em maior ou menor grau, em torno do Estado. A primeira o enquadra por meio da promulgação de uma ordem constitucional garantidora dos direitos individuais e das liberdades públicas; a segunda requer sua atuação eficaz na regulação dos mercados, na implementação de políticas distributivas e na promoção de transferências de renda no âmbito da sociedade; a terceira pressupõe o fortalecimento dos poderes das instituições encarregadas de assegurar a proteção dos interesses pós-materiais, como é o caso dos tribunais e do ministério público.

A cada nova geração dos direitos humanos, conforme se vê, um dos poderes do Estado-nação - respectivamente, o Legislativo, o Executivo e o aparato judicial, incluindo-se aí o Ministério Público - é afirmado, destacado e enfatizado. Com o fenômeno da globalização, no entanto, conforme já se viu, todos eles são funcionalmente esvaziados ou relativizados. Por isso, as três gerações de direitos humanos acabam enfrentando problemas para ser efetivadas. Seus valores básicos liberdades públicas, igualdade substantiva e afirmação dos interesses pós-materiais - colidem frontalmente com os imperativos categóricos da transnacionalização dos mercados, dos quais se destacam a eficácia, a produtividade e a competitividade. O cálculo econômico e a razão produtiva, em outras palavras, revelam-se potencialmente incompatíveis com os princípios básicos de convivência e sociabilidade no âmbito de formas organizacionais e institucionais dotadas de um mínimo de legitimidade jurídica e equilíbrio social.

Embora pareça evidente, convém pontuar que o surgimento dos direitos transindividuais, enquanto categoria de direitos específica, foi naturalmente precedido pelo surgimento e consolidação das coletividades de pessoas, movidas por interesses jurídicos comuns. Dessa forma, a aglutinação de interesses individuais, reunidos em torno de características ou circunstâncias comuns, fez posteriormente surgir um interesse diferente, próprio do grupo, não mais atribuível a um único titular ou a alguns poucos titulares.

Identificar, assim, o mote que inspira uma determinada reunião de pessoas, a fim de distinguir se o que os une configura um interesse coletivo comum ou uma coletividade de interesses comuns configura tarefa árdua, dada a linha tênue que separa os dois lados do problema e que diz respeito ao próprio surgimento dos direitos transindividuais.

Nada obstante, parece-nos suficientemente claro que essa onda aglutinante de interesses jurídicos é uma marca típica da modernidade, ao menos enquanto fenômeno capaz de se contrapor a outras categorias de interesses que, no limite, importam no confronto aos valores e princípios basilares inerentes à própria condição humana.

Luciano Velasque Rocha aponta que:

Ao lado do enaltecimento do indivíduo e de sua liberdade, a igualdade foi outro valor sobremodo caro ao ethos liberal. Contudo - e aí está o 
germe que nos séculos seguintes fomentará o surgimento não só de ações coletivas, mas de todo tipo de fenômeno coletivo - a igualdade conquistada não era senão uma aquisição formal. Não obstante formalmente iguais, os cidadãos remanesciam materialmente desiguais, tal como dantes.

A igualdade, enquanto valor, tem na sociedade moderna uma conotação bem distinta da que animou o ideário liberal da Revolução Francesa. Àquela época fazia sentido falar sobre igualdade enquanto conquista formal, eis que se tratava de inegável avanço para a sociedade de então: era o fim da servidão feudal e do jugo do déspota. O término do período revolucionário legaria à posteridade o advento da igualdade entre todos, aquisição histórica que não se pode menoscabar.

Todavia, a História - parece-nos - é uma marcha dialética e, portanto, sempre para diante. De uma tal maneira, a História conduziu o Estado à imperiosa necessidade de materializar a igualdade, enquanto conquista formalmente garantida - consciência despertada já no alvorecer do século $X X$. (2007, p. 15)

Dessa forma, os direitos transindividuais surgem e se consolidam num contexto típico de enfrentamento e contraposição de interesses. Não se trata da luta de classes propriamente dita, entre a burguesia e o proletariado, tal como concebida pela teoria marxista, mas sim de diversas lutas, entre diversas classes. Como destaca Luciano Velasque Rocha:

Se a Revolução Industrial fez com que gradualmente eclodissem as contradições internas que terminariam por sepultar as possibilidades da doutrina liberal, o pós-guerra de 1945 nos colhe na aurora da moderna sociedade de massas. É no seio desta sociedade que os meios de tutela tipicamente herdados do liberalismo hão de revelar toda sua insuficiência.

O típico "desprotegido" no capitalismo industrial do século XIX foi inegavelmente o trabalhador, que reagiu através da organização como força coletiva em torno de sindicatos e de movimentos grevistas. Foi a necessidade de assistir o trabalhador o grande responsável pelo advento do Estado Social em substituição ao Estado Liberal. Parece-nos igualmente acertado ver no consumidor o equivalente do trabalhador como ícone do desamparo na sociedade de massas do século XX. (2007, p. 25)

O mesmo autor pontua que esse nova realidade social e jurídica nasce a partir da falência do liberalismo econômico, concluindo que "o liberalismo transmite aos pósteros a herança da liberdade. O Estado Liberal é um Estado negativo; funciona tanto melhor quanto menos se imiscui na liberdade dos cidadãos" (Rocha: 2007, p. 6).

Ora, é nesse mesmo contexto histórico de declínio do Estado Liberal e surgimento do Estado Social que se inicialmente desenvolve 0 neoconstitucionalismo. $O$ contexto a que se faz alusão traz em seu bojo 
profundas mudanças, motivadas por fatores de todas as naturezas, desde a eclosão das duas Guerras Mundiais e todas as nefastas consequencias de um conflito desse jaez, até as mudanças econômicas e tecnológicas motivadas pela disseminação do uso da internet.

Não por acaso, o traço marcante do neoconstitucionalismo aproxima-o, ao menos quanto ao aspecto axiológico, dos mesmos fundamentos que lastreiam o surgimento dos direitos transindividuais, particularmente no que toca aos direitos de terceira dimensão.

A respeito das características fundamentais do neoconstitucionalismo, Humberto Ávila pontua que:

As mudanças propostas pelo neoconstitucionalismo, na versão aqui examinada, não são independentes, nem paralelas. Elas mantêm, em vez disso, uma relação de causa e efeito, ou de meio e fim, umas com relação às outras. O encadeamento entre elas poderia ser construído, de forma sintética, da seguinte forma: as Constituições do pós-guerra, de que é exemplo a Constituição Brasileira de 1988, teriam previsto mais princípios do que regras; o modo de aplicação dos princípios seria a ponderação, em lugar da subsunção; a ponderação exigiria uma análise mais individual e concreta do que geral e abstrata; a atividade de ponderação e o exame individual e concreto demandariam uma participação maior do Poder Judiciário em relação aos Poderes Legislativo e Executivo; o ativismo do Poder Judiciário e a importância dos princípios radicados na Constituição levariam a uma aplicação centrada na Constituição em vez de baseada na legislação. (ÁVILA, on-line)

Veja-se, no entanto, que há um traço marcadamente principiológico subjacente a ambos os fenômenos jurídicos, ou seja, tanto o surgimento dos direitos transindividuais, como o próprio neoconstitucionalismo, aparecem como resposta à inadequação ou insuficiência do modelo liberal, pautado exclusivamente pela subsunção do fato concreto à norma geral e abstrata preexistente e validamente produzida pelo Poder Legislativo, como mecanismo jurídico e processual para a solução de conflitos massificados.

\section{CONSIDERAÇÕES FINAIS}

Em face do que fora exposto, conclui-se que o Direito Constitucional tem se mostrado como um ramo suscetível à mudanças, principalmente no que concerne aos métodos interpretativos e à nítida busca de concretização dos valores previstos na Constituição.

Assim, como consequência imediata do neoconstitucionalismo, verifica-se o aparecimento e fortalecimento do ativismo judicial, como resultado da busca incessante pela materialização das garantias constitucionalmente previstas, o que pode ser constatado, por exemplo, pela análise do atual entendimento acerca do Mandado de Injunção, a respeito do qual o Supremo Tribunal Federal tem entendido ser conveniente solucionar, editando a norma no caso concreto, em face da omissão e mora e principalmente do Poder Legislativo. 
Enfim, nota-se certa saturação em relação às inadequações e insuficiência do antigo modelo liberal, no qual predominou o método de aplicação da lei ao caso concreto através de juízos de subsunção.

Nessa nova realidade jurídica, do neoconstitucionalismo, superada a sinonímia de lei e direito, prevaleceu os juízos de ponderação, atribui-se força normativa aos princípios que antecedeu, excedeu e controlou as leis, fortalecendo-se a jurisdição constitucional, de forma que o Poder Judiciário passa a ter, nesse contexto, melhores possibilidades de tutela adequadamente os direitos, dentre eles a categoria dos direitos transindividuais.

\section{REFERÊNCIAS}

ALMEIDA, F. D. M. Os Direitos Fundamentais na Constituição de 1988. Revista do Advogado. São Paulo, v. 28, no 99, p. 42-53, set. 2008.

ÁVILA, H. "Neoconstitucionalismo": Entre a "ciência do Direito e o "Direito da Ciência". Revista Eletrônica de Direito do Estado (Rede). Salvador: Instituto Brasileiro de Direito Público, no 17, jan./mar. 2009. Disponível em:

$<$ http://www.direitodoestado.com.br/rede.asp>. Acesso em 3 out. 2010.

AZEVEDO, A. J. O Direito Ontem e Hoje: Crítica ao neopositivismo constitucional e à insuficiência dos direitos humanos. Revista do Advogado. São Paulo, v. 28, no 99, p. 7-14, set. 2008.

BARCELlos, Ana Paula. A Eficácia Jurídica dos Princípios Constitucionais o Princípio da Dignidade da Pessoa Humana. Rio de Janeiro: Renovar, 2002.

BARROSO, Luis Roberto. Neoconstitucionalismo e Constitucionalização do Direito (o triunfo tardio do Direito Constitucional no Brasil). In Revista de Direito Constitucional. V. 58, São Paulo: Revista dos Tribunais, 2007.

BOBBIO, Norberto. Dicionário de Política. 6. ed., Brasília: Ed. da UnB, 1994.

BRASIL. Código Civil, Código de Processo Civil, Código Comercial, Legislação Civil, Processual Civil e Empresarial, Constituição Federal. Organização do texto: Yussef Said Cahali. 11. ed., São Paulo: Revista dos Tribunais, 2009.

CAMBI, Eduardo. Neoconstitucionalismo e Neoprocessualismo. Panóptica ano 01 no 6. Acesso em 19 out. 2010 em URL: www.panoptica.org.br.

CAMPILONGO, Celso. O Direito na Sociedade Complexa. São Paulo: Max Limonad, 2000.

CANOTILHO, J. J. GOMES. "Brancosos" e Interconstitucionalismo: itinerários dos discursos sobre a historicidade constitucional. Coimbra: Almedina, 2008.

FARIA, J. E. C. O. O Direito na Economia Globalizada. São Paulo: Malheiros, 2002.

FERRAJOLI, Luigi. A Soberania no Mundo Moderno. São Paulo: Martins Fontes, 2002.

FERREIRA FILHO, Manoel Gonçalves. Curso de Direito Constitucional. São Paulo: Saraiva, 2007.

HABERMAS, Jürgen. A Era das Transições. Rio de Janeiro: Tempo Brasileiro, 2003.

HESPANHA, B. O Direito Processual e a Constituição: a relevância hermenêutica dos princípios constitucionais do processo. Revista de Direito Constitucional e Internacional. São Paulo, nº 48, p. 7-90, jul./set. 2004. 
JELLINEK, Georg. Teoria General del Estado. Buenos Aires: Albatroz, 1954.

KELSEN, Hans. Teoria do Estado e do Direito. São Paulo: Martins Fontes, 2009.

LASSALE, Ferdinand. A Essência da Constituição. 6. ed., Rio de Janeiro: Lúmen Júris, 2001.

LENZA, Pedro. Direito Constitucional Esquematizado. 13. ed., São Paulo: Saraiva, 2009.

MARINONI, Luiz Guilherme. Curso de Processo Civil, vol. 1. Teoria Geral do Processo. 3. ed., rev. atual. São Paulo: Revista do Tribunais, 2008.

NEVES, Marcelo. A Constitucionalização Simbólica. São Paulo: Martins Fontes, 2007.

Transconstitucionalismo. São Paulo: Martins Fontes, 2009.

OMMATI, J. E. M. O Desafio posto pelos Direitos Sociais no Paradigma do Estado Democrático de Direito. Revista Latino-Americana de Estudos Constitucionais. Belo Horizonte, nº 6, p. 469-484, jul./dez. 2005.

ROCHA, L. V. Ações Coletivas: o problema da legitimidade para agir. Rio de Janeiro: Forense, 2007.

SARMENTO, Daniel. O Neoconstitucionalismo no Brasil: riscos e possibilidades. Acesso em 19 out. 2010 em URL: www.editoraforum.br/sit/conteudo/lista.

TEUBNER, Gunter. O Direito como Sistema Autopoiético. Lisboa: Fundação Calouste Gulbenkian, 1993.

VIGO, Rodolfo Luis. Constitucionalización y Neoconstitucionalismo: riesgos y prevenciones. 1. ed., In GREGOR, Eduardo Ferrer Mac. et. al. (coord.). La Ciência Del Derecho Procesal Constitucional. Santa Fé: Rubinzal-Culzoni, 2009.

ZAGREBELSKY, Gustavo. El Derecho Dúctil. Madrid: Trotta, 2009.

El Juez Constitucional en el Siglo XXI in: Revista Iberoamericana de Derecho Procesal Constitucional, n 10, jul./dez., 2008. 